\title{
Sobre osos e imposibilidades
}

\author{
On bears and impossibilities
}

\section{JOSÉ BERGUA*}

Resumen: Lo real se resiste a las figuraciones científicas y las manipulaciones políticas. El artículo aplica este punto de vista al conflicto ocasionado por la introducción de osos en los Pirineos, Surge a mediados de los 90, cuando el Ministerio de Medio Ambiente francés, apoyado por las asociaciones ecologistas y un amplio abanico de partidos políticos, artistas y personajes públicos de Francia, obtiene apoyo y financiación de la Comunidad Europea para introducir plantígrados en los Pirineos. La ejecución del proyecto está plagada de anomalías. Esos fallos son lo real. Tienen que ver con las condiciones sociales, naturales y socionaturales en las que se apoya el plan y que nos anuncian otros modos de ser de lo social, de lo natural y de las relaciones entre lo social y lo natural. Se propone hacer formar parte de lo real tanto a los fallos como a lo natural, lo social y lo socionatural que se resisten a la construcción. La sociología de lo real que se aplicará intentará explicar las condiciones sociales de los fallos y de las resistencias

Palabras clave: Rural, medio ambiente, osos, paisaje, ecologismo

\begin{abstract}
The real constantly bucks against scientific figuration and political manipulation. This standpoint is applied here to the conflict that arose in the mid-1990s, when the French Environment Ministry won EU backing to reintroduce brown bears in the Pyrenees with the enthusiastic support of ecologists, political parties from across the ideological spectrum, celebrities and public figures. The project was plagued by hitches, however: manifestations of the real. These problems affected the social, natural and socionatural conditions of the scheme, and they point to the existence of other social and natural spheres of being and to unforeseen relationships between the social and the natural. This paper will argue that the real must be made to embrace both the project's failings and the natural, social and socio-natural spheres which are so resistant to
\end{abstract}

\footnotetext{
* Docente de la Facultad de Economía y Empresa, Universidad de Zaragoza, Zaragoza, España. Miembro de la Red Iberoamericana de Investigación en imaginarios y Representaciones. Código ORCID: org/0000-0002-1134-9377 Contacto: jabergua@unizar.es
} 
intellectual construction. The sociology of the real applied will thus seek to explain the social conditions underlying the project's failings and the resistance it stirred up.

Keywords: Rural, environment, bears, countryside, environmentalism

\section{Introducción}

$\mathrm{D}$ espués del tsunami constructivista, el ciclón del actor red y otras tormentas relativistas, parece inevitable preguntarse serenamente por lo real. Pero no por la realidad construida o "ensamblada", que diría Latour (2005), sino por lo real que se resiste a dicha construcción o ensamblaje haciéndolos fracasar. El problema es que, como "sólo podemos describir y explicar el fracaso justamente con aquellos conceptos que hemos utilizado para construir (o ensamblar) las estructuras fracasadas, eso jamás puede transmitirnos una imagen del mundo al que pudiéramos hacer responsable del fracaso" (Watzlawick, 1995, p. 74-75). Pero lo real no tiene sólo que ver con el fracaso permanente de los dispositivos de conocimiento e intervención. Se deduce de la existencia de tales fracasos que lo real es también una "resistencia" (a cualquier reflexión o praxis), aunque más bien convendría decir que "tiene la condición de resistente" (Heidegger, 1993, p. 230-231).

En el psicoanálisis lacaniano, el registro de lo real es interpretado de un modo muy parecido. "Hablo de lo real — dice Lacan - como imposible en la medida en que creo que lo real es sin ley. Para tratar con ello se precisa una lógica del "no-Todo" (Stavrakakis, 2010, p. 65-70) que Lacan siempre relacionó con lo femenino, caracterizado por estar en situación de falta (o de exceso, todo depende del lugar desde el que se observe) en relación a una totalidad autoinstituida en términos masculinos. En efecto, dice Lacan (1992a, 1992b) que no toda la mujer ha sido edipizada sometida a las estructuras inconscientes en las que el padre, la genitalidad masculina y cierto tipo de placer sexual ocupan un lugar tan importante. Añade que la experiencia clínica demuestra que la mujer siente cierto malestar inconsciente porque no termina de reconocerse en el inconsciente instituido, pero ese malestar es inexpresable y difícilmente interpretable por el terapeuta. Sugiere Lacan que esa diferencia previa al inconsciente instituido, la mujer, aunque no la sabe, la experimenta en su goce sexual diferente, un goce que poco tiene que ver con el del varón. Ese goce diferente remite directamente a un más allá de Edipo. Ese inconsciente femenino (que es un inconsciente del inconsciente) tiene que ver con la experiencia de Dios. Pues bien, esta lógica del no-todo es aplicable a cualquier parte faltante del mundo, como los pueblos en relación a las ciudades, los niños-adolescentes-jóvenes en relación a los adultos, el demos en relación al kratos que la democracia dice unir (Bergua, 2015).

Lo real lacaniano está construido a partir de su noción de "goce", la cual, deriva de la "pulsión de muerte" freudiana. En 1920 Freud (1992, p. 272-333) sugirió que en la «compulsión de repetición» de situaciones desagradables que ejecutan los neuróticos en la transferencia y algunos niños con sus juegos, aunque en principio sirve al sujeto para dominar una violenta impresión, también tiene que ver con la insistencia de algo implícito al símbolo y que le precede. Freud dijo de esa insistencia que tiene que ver con "una tendencia de lo orgánico vivo a la reconstrucción de un estado anterior". Dicho de otro 
modo, la vida no sería sino un rodeo forzado por las derivas de la evolución que la muerte siempre estaría intentando amortiguar. Por lo tanto, la muerte, según la interpreta el psicoanálisis, es una pulsión que lleva a regresar a lo preconstituido, la base informe sobre la que se asienta el orden. Jung, por su parte, dice de la muerte que hace referencia a dos cosas. Por un lado, alude a lo totalmente indiferenciado, al Pleroma, que supone la muerte total. Por otro lado, a los muertos que vagan sin haber definido aún su destino. Es decir, a aquellos que no alcanzaron a diferenciarse pero que tampoco han caído en la total aniquilación y vagan perdidos buscando vida y sentido (Nante, 2011, p. 388). Desde la psicología transpersonal, Wilber (1995, p. 95-97) dice que ese fondo de indistinción al que atrae la pulsión de muerte cumple la función de permitir deshacer el orden instituido y facilitar así la emergencia de nuevas estructuras. Esta función es muy parecida a la de Shiva, el dios más venerado del hinduismo. Deleuze y Guattari (1985, p. 332 y sigs.) van a parar al mismo sitio cuando subrayan la importancia del "cuerpo sin órganos", plano de inmanencia caracterizado por la libre circulación de flujos y que tiende a refractar la organización, la significación y la subjetivación.

Propongo aplicar este punto de vista acerco de lo real al conflicto ocasionado por la introducción de osos en los Pirineos, la cordillera que separa Francia y España. Surge a mediados de los 90, cuando el Ministerio de Medio Ambiente francés, apoyado por las asociaciones ecologistas y un amplio abanico de partidos políticos, artistas y personajes públicos de Francia, obtiene apoyo y financiación de la Comunidad Europea para introducir plantígrados en los Pirineos. Entre los autóctonos la decisión fue recibida con división de opiniones. La apoyaron sectores de la población vinculados al turismo y se posicionaron claramente en contra los más importantes colectivos de ganaderos y cazadores.

\section{Lo real natural}

Descubrir lo real natural que se le resiste al plan de introducción del oso decido por las más altas autoridades francesas, con el importante apoyo político y económico de la Unión Europea, exige prestar atención a los modos de gestionar la introducción y a los discursos encargados de legitimar dicha decisión. En las dos dimensiones hay fallos o anomalías. Esos fallos tienen que ver con una naturaleza que no se deja explicar y manipular del todo. En ese "no dejarse" reside lo real natural del oso

\section{Las narraciones}

Antes de ver cómo trabajan algunas de las unidades involucradas en la introducción del oso conviene echar un vistazo al trasfondo imaginario que anda detrás de esta controvertida política. En efecto, si nuestras instituciones y el movimiento ecologista que las apoya tienen tanto interés en poblar de osos las cordilleras es porque quieren incorporar lo "salvaje". Según Bobbé (2005, p. 124-125), ese término tiene un carácter polisémico pues se cruzan el significado tradicional y varios contemporáneos. El tradicional nos lo descubre la etimología: "salvaje" deriva de silvaticus ("hecho en la silva"). En el siglo XII se aplica a los animales carnívoros que viven en los bosques, desiertos u otros lugares alejados de los hombres y en el siglo XIII se opondrá a 
“doméstico", el ámbito de la casa (domus) y representará una amenaza para el ser humano y sus producciones. En la actualidad hay una nueva cultura de lo salvaje que tiende a asociar lo salvaje a lo "natural" (opuesto a lo "artificial") y ya no, como sucedía con la noción tradicional, a lo "peligroso". Este deslizamiento semántico ha sido promovido muy especialmente por los amigos de los animales, que son defensores de su "estado de libertad natural". Bobbé dice que, una vez redimido de su peligrosidad, el animal salvaje se convertirá en parte de las operaciones de labelización de productos artesanales y de los mismos territorios que dicho animal ocupa.

Por otro lado, Bobbé ha comprobado que la reinterpretación de lo salvaje se ha hecho en clave mítica. Tras analizar 150 relatos mediáticos sobre osos abatidos desde 1921 en los Alpes a 2004 en Lescun, año y lugar en que se disparó a Canelle, la última osa autóctona del Pirineo ha comprobado que el esquema mítico al que se someten las noticias y comentarios periodísticos es muy similar al descubierto por Propp en sus análisis sobre los cuentos maravillosos (p. 128). Primero, está la desaparición del último oso alpino, equivalente a la "pérdida" del objeto. Segundo, el proyecto de reintroducción equivale a la "búsqueda" del objeto que falta. Tercero, la política de información y sensibilización evoca el tema de la "prueba". Y cuarto, tratándose de una operación en curso, sólo el condicional puede ser utilizado para evocar la "adquisición" del objeto perdido.

Esta base mítica contribuye a legitimar la fabricación social de un salvaje que Bobbé califica como "de primer tipo". Tal salvaje se caracteriza por habérsele retirado el derecho de comportarse como tal" (p. 133). Esto exige, por un lado, construir una infraestructura que impida la depredación del oso. Es lo que se ha hecho, por ejemplo, al habilitar una línea telefónica especial reservada a la localización de los osos reintroducidos. De este modo se pretende prevenir daños y actuar después de que ocurran pues así se reactivaría la polémica sobre la reintroducción. Por otro lado, además de impedir la depredación a la que el oso tiende, es necesario hacerle un hueco entre los humanos y sus costumbres. Se ha hecho bautizándolo, es decir, poniéndole nombre (esto incluso ha llegado a ser objeto de concurso en las escuelas) y otorgándoles padrinos y madrinas (como Carla Bruni).

Si continuamos con Bobbé, el oso que habita los Pirineos es un salvaje de "segundo tipo" pues no se interviene física ni directamente sobre él, como se hace con los salvajes de primer tipo, más directamente controlados, sino que se trabaja el territorio que habita. Los convenios de espacios protegidos transfronterizos y la ampliación de parques son un buen ejemplo de esto. A lo que no llega nuestro oso es a ser un salvaje de "tercer tipo" (pp. 139 y ss.). Es el caso de los perros convertidos en salvajes. Se diferencian de las otras clases de salvajes en que tiene un estatuto legal de especie doméstica y actúa espontáneamente sin que nada pueda prever sus intenciones. Por lo tanto, "la fabricación (indirecta) de este salvaje de tercer tipo resulta de un relajamiento de la presión humana o de un fracaso del hábito de la domesticación” (p. 141).

\section{La red científico-técnica}

E1 19 de mayo de 1996, a las 8,10 h., fue soltada en Melles (Alta Garona), ante un selecto puñado de espectadores, Ziva. Una semana antes el equipo francés encargado de la captura había despedido en Eslovenia a los especialistas agrupados en torno a Djuro 
Huber, veterinario de origen croata y profesor de biología en la Facultad de Medicina de Zagreb (De Marliave, 2003, p. 173). Este hombre había seguido las negociaciones de la compra de osos porque en la reserva de Medved hay plantígrados con características similares a las de los pirenaicos. En efecto, Jean Bouvet y Pierre Taberlet (2001) habían construido el árbol genealógico de las dos familias de oso pardo europeas (EscandinaviaBalcanes-España y Rusia-Rumanía) y comprobaron que sólo la primera convenía y que, dentro de ella Eslovenia, resultaba el lugar de provisión más factible (p. 182).

Después de cazar al oso, lo ficharon, le pusieron un collar emisor y lo trasladaron por avión en una cápsula, similar a la de los cosmonautas, vigilada por una cámara de televisión. Una operación similar a ésta se había realizado ya para soltar a Mellba (el 6 de junio de 1996) y Pyros (el 2 de mayo de 1997). En los tres casos, para mantener controlados a los osos se les colocó un emisor de VHF en el collar que enviaba dos bips por segundo a un receptor conectado a una antena. Para resultar más efectivos en el trabajo de control se utilizó un avión ligero que hacía rebotar los bips emitidos. El avión se decidió que sobrevolara el territorio un día a la semana en intervalos de 30 minutos. Esta vigilancia tan intensa recibió la colaboración la Escuela Superior de Electrónica de Toulouse, pero no tuvo el éxito esperado porque los osos se rebelaron. En efecto, poco antes de su muerte en septiembre de 1997, Mellba se desprendió de su collar. Pyros "perdió" el suyo el 22 de agosto de 1997 (pusieron uno nuevo el 5 de Abril de 1998) y Ziva, por su parte, se deshizo de otro a la salida de la hibernación en 1999 (p. 181).

Pero todo es bastante más complejo. Detrás de cada plantígrado hay una compleja trama burocrática, económica, tecnológica y científica que va mucho más allá de la vigilancia con collares y aviones. Su nacimiento se puede remontar a enero de 1995, fecha en la que se constituyó la Red y el Comité de Seguimiento de la Población de Oso Pardo del Pirineo Occidental en el marco del proyecto LIFE hispano francés de Conservación de Vertebrados Pirenaicos Amenazados (Herrero y Alcántara, 1997). En la primera reunión del Comité se acordó que el Gobierno de Aragón llevaría a cabo durante dos años un programa de búsqueda de huellas y señales de oso pardo con la misma metodología general que ya habían utilizado la parte francesa y Navarra. En Aragón, durante el mes de Febrero de 1995, diseñaron y acondicionaron 26 recorridos fijos por el área osera tradicional y zonas adyacentes con una longitud de aproximadamente $8 \mathrm{~km}$ cada uno. En el valle de Ansó había 6, los mismos que en Echo, 4 en Aragüés-Jasa y 4 en Aísa.

Los recorridos se realizaron entre abril y diciembre. Estaban todos acondicionados con 5 "estaciones de huellas" y 5 "estaciones de olor". Las estaciones de huellas consistían en pequeñas superficies de tierra rastrillada de entre 1 y 2 metros cuadrados. Las estaciones de olor eran mallas desflecadas embebidas de trementina y clavadas en pinos rojos (pin royo en aragonés), abetos y robles. También se dispusieron carroñas (ovejas muertas) en algunos recorridos y al lado de las estaciones de huellas. Además de los recorridos fijos se realizaron otros de manera libre. Por otro lado, durante abril y mayo se llevaron a cabo dos operaciones de prospección adicionales. En conjunto se llevaron a cabo 272 recorridos (30.204 kms.) Los resultados obtenidos no estuvieron a la altura del enorme esfuerzo invertido. Sólo se registró un indicio de oso seguro.

Además de la obtención de indicios, el programa de reintroducción del oso incluía más apoyos (Sáinz de la Maza y Nunes Alonso, 2001). En Cataluña, por ejemplo, las energías se centraron en la evaluación de la aclimatación del animal al territorio. Entre los trabajos dirigidos a tal fin destacan los realizados por el LIGIT (Laboratorio de 
Información Geográfica y Teledetección) de la Universidad Autónoma de Barcelona entre finales de 1997 y la primavera de 2000 en colaboración con el Servicio de Fauna del Departamento de Medio Ambiente de la Generalitat de Catalunya. Primero se construyó un "Modelo de Interés Trófico" a partir de un solo factor (la vegetación) identificando las especies más apetecidas por el oso y atribuyéndoles valores de interés trófico entre 1 y 10 . Por otro lado, se elaboró un "Modelo de Interés de Refugio" para averiguar los lugares potenciales de hibernación. Finalmente, se estudió la selección del hábitat realizada efectivamente por el oso (según el seguimiento telemétrico del que era objeto por un equipo francés y otro catalán) contrastando ese dato con la disponibilidad de hábitats. Los resultados de tan compleja investigación indican que el hábitat frecuentado por los osos se sitúa en alturas medias, entre 1300 y 1800 metros de altura (un poco más bajas en primavera y otoño, algo más altas en verano), bastante escarpadas (con pendientes de entre 30 y 60 grados) y a cierta distancia de zonas frecuentadas por los humanos. También se comprobó que el comportamiento de Pyros era bastante estable mientras que Ziva buscó hábitats más variados y también de más difícil acceso. Lo que no aclaró el informe es la razón de esa diversidad de gustos.

Otro asunto que interesó a los responsables de la reintroducción del oso durante los primeros años fue la recogida y análisis de heces. Se realizó en colaboración con el servicio francés de alimentación ENVT (Lagalisse, Quenette, Rech y Ligereux, 2003, p. 639-644). El territorio objeto de inspección fue de $7000 \mathrm{~km}$. cuadrados repartidos en tres departamentos: Alta Garonne, Ariège y Altos Pirineos. Durante los tres años se recogieron 89 muestras de heces. Teniendo en cuenta que un oso defeca una media de dos veces por día durante 8 meses de actividad anual y que había 2 osos en 1996, 3 en 1997 y 4 en 1998 y 1999 (los oseznos de Melba), las heces recogidas suponían un 1,9\% del total de deposiciones. Una vez congeladas se enviaban al ENVT para su análisis. Allí se comprobó que los animales eran básicamente herbívoros pues el 92\% de las muestras contenían elementos vegetales llegando el $51 \%$ de ellas a no contener otra clase de restos. También se comprobó que el 29,6\% de las heces contenían mamíferos (el 21,6\% salvajes) y que en el $22,1 \%$ había insectos. En base a toda la información obtenida se dedujo que el régimen alimentario global del oso estaba constituido por ungulados salvajes como rebecos y corzos (el 22,7\% del alimento ingerido tenía ese origen), los frutos secos de quejigos y hayas $(18,4 \%)$, roedores $(12,1 \%)$, insectos $(12 \%)$, plantas no herbáceas $(11,5 \%)$, mamíferos domésticos ${ }^{1}(9,5 \%)$ plantas herbáceas $(5,9 \%)$, etc. De modo que, según las investigaciones realizadas, los mamíferos constituyen el 44,3\% de la dieta y son el alimento clave ${ }^{2}$. Sin embargo, los expertos no pudieron averiguar si tales mamíferos habían sido matados por el oso o eran carroña. Tampoco han sabido explicar estos expertos por qué a Franska le gustaba más matar ovejas que comerlas.

\footnotetext{
1: Otros expertos dicen que el $90 \%$ de la depredación tiene por objeto las ovejas. Un oso mata una media de 1,5 ovejas por ataque. El número de ataques es más importante en los pirineos centrales y orientales que en los occidentales (Camarra, 2005, p. 22)
}

2: Más información sobre la dieta del oso pardo puede verse en Huet (2005, p. 49-56) 


\section{Lo natural imposible}

La red de investigaciones construida en torno al oso que hemos visto ha tenido como función servir de apoyo a la labor técnica de introducción del animal. Al estar protagonizada por científicos ha permitido conocer mejor sus hábitos. En base a ese conocimiento los políticos y responsables del proyecto han tomado decisiones. Sin embargo, como hemos comprobado, no todos los hábitos del oso se dejan entender por la ciencia ni, en consecuencia, tratar por la política. En efecto, a pesar de la gran cantidad de datos obtenidos y las potentes herramientas utilizadas, la ciencia no sabe interpretar la variación de gustos que mostraban Pyros y Ziva a la hora de seleccionar los hábitats. Tampoco, son capaces de asegurar los científicos si los restos de mamíferos ingeridos corresponden a animales abatidos por el oso o que estaban muertos ya. Del mismo modo, resulta sorprendente que tras los $30.294 \mathrm{kms}$ recorridos por el Pirineo aragonés occidental en busca de huellas de osos sólo se pudiera encontrar un "indicio seguro". Finalmente, varios osos han logrado desprenderse de los localizadores y volverse invisibles.

Todas estas lagunas de conocimiento acerca del comportamiento del plantígrado seguramente han afectado a las decisiones tomadas por los políticos en el sentido de que habrán dejado algo de la vida del oso sin atender. Por lo tanto, frente a la parte del animal construida solidariamente por científicos (que conocen) y políticos o profesionales (qué actúan) hay otra de la que nada se sabe y con la que no se puede hacer nada. Esa parte oscura que se sustrae a la construcción social remite a la dimensión real del oso.

Pues bien, podemos decir del oso que es un ente híbrido. No en el sentido de que mezcla o combina una dimensión social construida por distintos agentes, tal como sugieren la teoría del actor red (Callon, 1986). Más bien porque mezcla toda esa construcción social con una realidad que se sustrae y refracta dicha construcción. Tal cosa es lo real en el oso.

\section{Lo real socionatural}

Si lo real tiene que ver con lo que insiste en manifestarse pero se resiste a ser comprendido y gestionado, es obvio que, en el caso de la introducción de osos, no sólo tiene que ver la "naturaleza" del animal, También hay una dimensión "socionatural" de lo real pues la trama política liderada por las administraciones y el movimiento ecologista que introduce y gestiona al oso y su entorno natural, ha encontrado resistencia en otra trama, esta vez encabezada por colectivos de ganaderos y cazadores, que tiene otras relaciones con la naturaleza y que crean otro tipo de imposibilidad.

\section{Ganaderos y cazadores}

Para entender la oposición que despierta entre ganaderos y cazadores el plan de introducción de osos, sugerido por los ecologistas y llevado a la práctica por una compleja trama político-administrativa, parte de ella mostrada más arriba, es necesario hacer algo de historia (Benhamou y Mermet, 2003; Benhamou, 2005)

Todo comienza con las tentativas de los años 80 para concertar una gestión de la población de osos bearnesa (El Plan Ours francés de 1984 y la Directiva Osos europea 
de 1988) que encontraron una gran resistencia entre los autóctonos dando lugar a lo que, con posterioridad, algunos han denominado "guerra del oso". Ciertos actores locales (electos, cazadores y profesionales agrícolas), ayudados por el Ministerio de Agricultura, lograron en 1993 que les fuera confiada la gestión del oso. Para tal fin se creó en 1994 un sindicato mixto, La Institución Patrimonial del Alto Béarn (IPHB). El Ministerio de Medio Ambiente nunca estuvo de acuerdo con la política del IPHB. Así que, en 2005, tras la muerte fortuita de la osa Canelle a manos de un cazador, el ministro de Ecología Serge Lepeltier, más decidido que su antecesora Rosyne Bachelot, aprovechó la ocasión y decidió apostar por la introducción de osos y alcanzar en 2008 la cifra de 30 ejemplares.

Un segundo foco de conflicto respecto al oso se encuentra en los Pirineos centrales. Un grupo de electos del Alto Garona decidió crear en 1991 ADET (Asociación para el Desarrollo Económico y Turístico del valle alto del Garona). Su finalidad fue reintroducir el oso para valorizar económica y ecológicamente la zona. La respuesta no se hizo esperar. La primera movilización hostil al oso la impulsó ADIP (Asociación de Defensa de la Identidad Pirenaica), creada ya a mediados de los 80 por los cazadores y reactivada en 1999 por un grupo de ganaderos y electos de la región de Luchon (Alta Garona) pues los osos reintroducidos habían comenzado a desplazarse por distintos valles. Por otro lado, ese mismo año, un grupo de ganaderos de Ariège respaldado por algunos electos locales se opuso a la política pro-oso a través de las estructuras sindicales departamentales.

A partir del 2000, el conflicto se redimensionó. Los recorridos de un oso subadulto de origen esloveno, Nere, hacia el corazón de los Altos Pirineos desencadenó una fuerte contestación del País de Toy (Baréges, Luz-St-Sauveur) organizada alrededor de electos como el alcalde de Luz-St-Sauveur (Claude Massoure), algunos cazadores y la responsable del sindicato ovino de Baréges-Gavarnie. Para agrupar las fuerzas hostiles al oso crearon la ASPP (Asociación para la Salvaguarda del Patrimonio Pirenaico). En la zona Baréges-Gavarnie también se posicionó contra la presencia de osos el sindicato de ganaderos AOC. Ajeno a los conflictos que su presencia desencadenaba, Neré continuó su marcha por los valles pirenaicos de una y otra vertiente y llegó al Alto Béarn. En ese preciso momento los dos focos del conflicto se unieron y la "guerra" se redimensionó, alcanzando ya a gran parte del macizo pirenaico. En la primavera de 2001 ambos frentes se agruparon en torno a un discurso de oposición radical. Fue dado a conocer en marzo del mismo año con la publicación del manifiesto "La cólera de los Pirineos".

Esta brevísima historia de la oposición a la introducción del oso muestrea que lo imposible de representar y gestionar, así como su insistencia en manifestarse, no tiene ya que ver con una naturaleza que refracta la socialización, sino con la imposibilidad de que los sueños urbanos acerca de la naturaleza se realicen. Los responsables de esa imposibilidad son, en general, los pueblos. Más exactamente, la parte que no encaja en lo que las ciudades quieren ver en ellos. Quienes agencian esa imposibilidad son, principalmente, los cazadores y ganaderos.

Si tiramos de esta idea, lo real parece tener que ver con el hecho de que la relación de dominación ejercida por las ciudades contra unos pueblos, que son vistos y gestionados como "objetos", no termina de funcionar. Téngase en cuenta que en la modernidad las ciudades comenzaron su reinado convirtiendo a los pueblos en objeto de explotación (económica y demográfica) (Williams, 2002: 80; Rifkin, 2002: 200; Ibáñez, 1991, p. 98), luego se volvió imaginariamente a ellos para convertirlos en objeto de inspiración 
ideológica (como ocurre con cierto nacionalismo y algún ecologismo) y finalmente fueron vistos y gestionados como objeto de disfrute estético y de ocio o vacación (Bergua, 2009). De este orden formaría parte la introducción de osos, pues ha sido defendida como un atractivo turístico que beneficiará a los pueblos. Pues bien, la insistente resistencia de cazadores y ganadores muestran la imposibilidad de que este orden se realice.

\section{Ciudades y pueblos}

Sin embargo, el carácter social de lo real en este asunto del oso tiene que ver con más cosas. Por ejemplo, con el hecho de que las luchas contra su introducción impiden que el modo urbano de pensar y tratar a la naturaleza, así como de relacionarse con ella, ambos distintos de los que tienen las gentes de los pueblos, al menos los cazadores y los ganaderos, se realice.

En efecto, los pueblos tienen una relación de vecindad y proximidad con la naturaleza de la que carecen las ciudades, pues, sea cual sea el trabajo que tengan los habitantes de los pueblos, por el hecho de vivir en ellos, ya a través de los sentidos (vista, oído, olfato) la experiencia que puedan hacer de la naturaleza es en principio más directa que en las ciudades. Esta es probablemente, la diferencia más notable entre las ciudades y los pueblos: las primeras se relacionan con la naturaleza distinguiéndose de ella (sociedad/naturaleza), mientras que los segundos tienden a establecer relaciones de acoplamiento e incluso hibridación (sociedad-naturaleza).

Para entender la diferencia entre el modo urbano de relacionarse lo social y lo natural que se ha instituido en la Modernidad y el lugar que ocupa el modo practicado por los pueblos conviene hacer algo de historia. Para el hombre anterior a la modernidad la naturaleza era algo que se percibía con miedo y que tenía un carácter demoníaco. Esta visión encaja bastante bien en el contexto de una sociedad influida por una religión que considera pecaminoso todo lo natural y todo lo femenino. Por eso en pintura, por ejemplo, el tema paisajístico no existe. Aún en el siglo XV, a pesar de que la naturaleza atrae a ciertos artistas, todavía es muy poderosa la influencia religiosa que aparta al hombre de ella. En esa época Petrarca se convirtió en el primer europeo en trepar, por placer, a la cima de un pico, el Mont Ventoux, cercano a su casa de Vaucluse en la Provenza francesa. La experiencia le produjo un gran sentimiento de culpabilidad pues la belleza que se le ofrecía sentía que podía alejarle de Dios (Williams, 2002, p. 164). En cambio, en esa época, los chinos llevaban ya más de diez siglos enamorados de la belleza de la naturaleza indómita. Y es que las montañas, para los chinos y otros pueblos orientales, siempre han estado íntimamente relacionadas con la espiritualidad (Keswick, 1993, p. 49) en incluso el I Ching interpreta los trigramas haciendo permanente referencia a ella (Chaoying y Durand, 2000, p. 67-69).

A medida que nos alejamos de la Edad Media y nos aproximamos a la Modernidad, podemos observar que la opinión que se tiene de lo natural cambia. Pero no se trata de que se valore positivamente, como sucede entre ciertos pintores, pues aún tendrá connotaciones negativas, sino de que ya no se la teme. Trías (1999) ha recogido la opinión que a mediados del XVIII tenía un viajero de los Alpes: "esas formas caóticas carentes de gracia y de belleza, ese compendio de horrores y fealdades que son los Alpes con sus repugnantes extensiones nevadas, malformaciones irregulares y glaciares". Estamos en los comienzos de la Revolución Industrial, en vísperas de la Revolución 
Francesa y a poco más de un siglo de que Nietzsche certifique la muerte de Dios. Por eso la opinión del viajero es tan moderna. Y lo que se ve en ella no es un distanciamiento de la naturaleza porque sea fuente de mal. Más bien se observa una actitud arrogante. Si el hombre moderno ya no teme a la naturaleza y se puede permitir el lujo de mirarla con desprecio es porque ha logrado dominarla.

Este dominio se realizará de dos modos. En el plano económico, la actividad industrial sustituirá las relaciones de acoplamiento y cohabitación que, en cierto modo, caracterizan a las actividades primarias, las más importantes en la premodernidad, por otras de explotación que incrementarán el orden social interno generando cada vez más desorden y degradación en el ecosistema natural. Por otro lado, en el plano cognitivo, el hombre moderno se lanzará sobre la naturaleza armado con un nuevo modo de conocer, la ciencia, tan agresivo y violento como la actividad industrial. En este sentido, conviene recordar a Bacon, uno de los apólogos del método experimental, cuando sugiere colocar a la naturaleza en el potro de tortura y extraerle todos sus secretos (Getty, 1996, p. 28). En definitiva, tanto en el plano económico como en el científico, la naturaleza es convertida por el hombre moderno en un objeto. Este es el contexto en el que habla de los Alpes el viajero del siglo XVIII.

A la consideración de la naturaleza como objeto de explotación y de conocimiento científico, acompañará siempre, como una sombra, el regreso imaginario a ella. Estos dos movimientos, diferentes pero complementarios, van a ser una constante de la Modernidad. Sin embargo, para que este segundo paso se dé es necesario que el hombre se sienta saturado y desbordado por la creciente artificiosidad de la sociedad moderna. Este sentimiento es posible encontrarlo ya en los orígenes de la Revolución Industrial. Así se lamentaba por aquella época el escritor inglés Charles Jenner: "no diviso ningún claro verde, ningún riachuelo, ninguna fuente burbujeante desde la rocosa colina" (Williams, 2002, p. 189). Este ánimo se generalizará en la segunda mitad del siglo XIX. Coincidiendo con un optimismo casi generalizado en la capacidad del hombre para dominar y conocer la naturaleza, surgirá entre ciertas élites el deseo, cada vez más poderoso, de regresar a ella. En efecto, en el siglo XIX, distintas gentes llamaron la atención sobre el deterioro del entorno medioambiental, impulsaron una apropiación estetizante y romántica de parajes y especies amenazados por la industrialización, se impulsaron prácticas naturistas como el vegetarianismo o el nudismo y aparecieron viajeros que buscaron una naturaleza lo más virgen y desconocida posible.

Fueron precisamente estos viajeros los que descubrieron algunos de los parajes hoy más protegidos por la legislación y más visitados por los turistas. En el caso del Pirineo oscense los viajeros venían de Francia y las bellezas naturales que más les sedujeron fueron los Pirineos y el Prepirineo de la Sierra de Guara. Muchos de ellos, por ejemplo, Lucien Briet, pasarán de la mera contemplación extática del Pirineo a sentir la necesidad de solicitar su protección. De hecho, el francés fue el principal responsable de que en 1918 el Valle de Ordesa, situado en el corazón de los Pirineos, se convirtiera en Parque Nacional. Ahora bien ¿cómo veían estos viajeros franceses a los pobladores de esas montañas?

Pues no les atrajeron sus gentes ni su acoplamiento con el entorno sino sólo la naturaleza (Biarge y Biarge, 2000, p. 359-360). En 1889 Albert Tissander decía de las aguas del río Alcanadre que sus aguas son de "color esmeralda" y que las rocas eran "pináculos colados como las catedrales" e incluso "obeliscos"). Por su parte, Franz 
Schrader, nacido y educado en una gran ciudad (Burdeos), describía así en 1877 el paisaje que se divisa desde Cotiella: "sólo a los decoradores les aconsejaría que subieran... Estamos en el cielo mismo, todo es luz, transparencia y destello, surgen rayos de luz de cada llanura y de cada montaña, los ríos que discurren a lo lejos parecen regueros de fuego blanco". En cambio, lo pobladores de tan bella naturaleza no saldrán muy bien parados. Dirá que "el mal estado de los caminos suele ir parejo con la mala calidad de la comida y no digamos de la limpieza". Por eso se lamenta: ¿Cuántas veces me tuve que conformar con huevos duros para comer? ¿Y cuantas veces opté por comer al aire libre, debajo de los árboles, ante la posibilidad de ser devorado por cualquier especie de insecto de difícil catalogación que campa a sus anchas en las habitaciones de las posadas?" ¿En qué reside entonces la belleza de los Pirineos para estos viajeros? Pues en una naturaleza de difícil acceso y, sobre todo, desprovista de cualidades humanas. De modo que lo que le sobra a la naturaleza para que al hombre urbano le resulte atractiva son sus pobladores, las gentes de los pueblos

Según lo anterior, lo que se resiste a la introducción del oso son las relaciones de cohabitación entre sociedad y naturaleza que practican los pueblos y que, para las ciudades, habituadas a distinguir lo social de lo natural (unas veces poniendo por encima a una parte y luego a otra), son imposibles de conocer y de gestionar. Como las resistencias a la dominación urbana, también la oposición a la relación con la naturaleza que las ciudades tratan de imponer forma parte de lo real. Es decir, de la "realidad" del oso.

\section{Naturalistas, totemistas y animistas}

Para que no haya equívocos, conviene añadir que las relaciones con la naturaleza que practican las ciudades y los pueblos son más complejas pues abarcan más asuntos que los tenidos en cuenta y que incluso intervienen en la guerra del oso. Uno de tales asuntos, si hacemos caso a Descola (2006), tiene que ver, con las ontologías que inspiran el modo como los humanos perciben a los no humanos y se relacionan con ellos.

La ciudad participa de una ontología "naturalista", caracterizada por suponer que unos y otros son muy similares materialmente. Tal cosa propone ver la ciencia cuando dice, por ejemplo, que el ADN del hombre y de la mosca del vinagre son idénticos, cuando experimenta en ratas o monos los fármacos destinados a humanos o cuando extrae de los cerdos el material para construir las válvulas que introduce en los corazones la cirugía cardíaca. También supone el naturalismo que humanos y no humanos son muy diferentes interiormente, pues nosotros tenemos alma y cultura, pero al otro lado no hay nada parecido. Tal es el modo como se opina en la civilización occidental desde Platón, pasando por el Cristianismo, hasta llegar al racionalismo de Descartes, para el que los animales, por ejemplo, son meras máquinas que no sólo no tienen razón o voluntad, pues hasta el instinto les falta (Simondon, 2008).

El ecologismo, que tiene antecdentes civilizacionales en los presocráticos y la interpretación de la naturaleza de San Francisco, entre otros, expresa un punto de vista "totemista" que también tiene su origen y hábitat principal en las ciudades, pero que difiere del naturalismo en que, quizás para liberarse de la mala conciencia que esa visión puede generar a quienes, por ejemplo, tienen trato corriente con animales domésticos 
(Derrida, 2008, p. 41-42), reconoce distintos grados de interioridad a los no humanos, lo que ha llevado a convertirlos en sujetos de derechos.

Los pueblos, por su parte, se relacionan con la naturaleza a partir de una ontología de tipo "animista" que, si bien considera que humanos y no humanos tienen interioridad, y esa característica puede facilitar el movimiento de las almas a través de los cuerpos, tal como se cree en distintas culturas (Doniger, 2005), distingue en los no humanos, del mismo modo que se hace entre los humanos, a los amigos de los enemigos, asunto éste que está muy presente en la cultura popular tal cual la expresan las fábulas de La Fontaine y Samaniego, los cuentos populares, los dibujos animados contemporáneos y distintos mitos.

En los Pirineos, el oso ha caído con frecuencia del lado de los enemigos, pero también hay un sustrato mítico que habla de relaciones más que fraternales (Casanova, 1997, p. 69-70). En el valle de Barèges, por ejemplo, es muy conocida la historia de María De Pasqua, una mujer que no podía tener hijos y que, después de hacer caso a los mayores del lugar, fue a ver a un gran oso al que se le atribuían poderes sobrenaturales y que vivía en la montaña de Ardiden. Tras oír el consejo del animal, hizo siete inmersiones en el lago del mismo nombre y al cabo de nueve meses tuvo un hijo. La mujer volvió seis veces más a ver al oso, hizo después sus inmersiones en el lago y tuvo otros tantos hijos. El animal exigió estar informado sobre su progenie, pero cuando María decidió dejar de tener hijos no visitó más al oso. Ante la falta de noticias de su amante, el oso bajó al pueblo y se la llevó. Desde entonces se cuenta que se la ve las noches de luna llena paseando por la orilla del lago. De la relación entre mujeres y osos tomó nota también un viajante musulmán procedente de India (Madurai) que en 1.348 visitaba el valle de Ossau (p. 70). Sus habitantes le contaron que eran descendientes de un oso y una princesa. Finalmente, también tienen que ver con esa relación entre humanos y plantígrados los secuestros de doncellas, contados en numerosas leyendas y representados en celebraciones, como la del día del oso, en San Llorenç de Cerdans.

Tan importante es en la ontología animista el reconocimiento de interioridad en los animales como la consideración de que humanos y no humanos, al contrario de lo que opina el naturalismo, son muy diferentes materialmente y que de esas diferencias brotan interioridades y modos de ser y comportarse también muy distintos.

Como se ve, aunque las ciudades tienen bloqueada su comunicación con los pueblos, podrían abrirla si son totemistas. El problema es que también aquí hay diferencias importantes. De hecho, el conflicto del oso es, principalmente, una guerra entre las posiciones totemistas del ecologismo y las animistas de cazadores y ganaderos. Para ponerse de acuerdo quizás el ecologismo debiera saber entender la condición de enemigo que tiene el oso para los de los pueblos, mientras que los cazadores y ganaderos tendrían que entender la condición de amigo que le atribuyen los ecologistas. El problema es que, si bien éstos tienen recursos imaginarios para protagonizar el cambio, a los otros les faltan.

\section{Lo socionatural imposible}

Ya vimos que el oso es real porque tiene una naturaleza que se resiste y de la que los gestores de la introducción no saben dar cuenta. Si pasamos a lo socionatural, según lo 
expuesto en este epígrafe, el oso introducido en los Pirineos es real e imposible en dos sentidos más.

Primero, porque el oso involucra a unos pueblos que tampoco la trama institucional termina de saber tratar, lo que ha generado frecuentes revueltas ${ }^{3}$.

Segundo, porque el plantígrado alude a una relación entre naturaleza y sociedad (la que expresan cazadores y ganaderos) de la que las ciudades no saben mucho por más que la gestionen, traten con ella e incluso la investiguen ${ }^{4}$.

\section{Lo neorrural imposible}

Finalmente, formarían parte de lo real, no sólo esas otras relaciones entre sociedad y naturaleza que acabamos de mencionar, sino otros modos de relacionarse los pueblos y las ciudades que el actual orden (construido en términos jerárquicos desde las ciudades) no es capaz de entender (Bergua, 2009).

Si con el tipo de sociedad instaurada en la modernidad el pueblo aparece como un objeto de explotación o intercambio desigual, como un objeto del conocimiento científico y como un objeto de inspiración ideológica, con la postmodernización se culmina la cosificación de los pueblos al convertirlos en objeto de consumo, pero se abre también la vía para que se inventen como sujetos y se establezcan relaciones no jerárquicas con las ciudades.

La postmodernización, según la interpreta Moyano (2000), tiene también su origen en las ciudades y se caracteriza por la aparición de una nueva sociedad en la que las actividades industriales son menos importantes que las postindustriales. Con este cambio la lógica de la explotación y degradación de la naturaleza tenderá a desaparecer. Esto es debido a que las energías y materias obtenidas de la naturaleza son hoy económicamente menos importantes que, por ejemplo, la información, el factor productivo emblemático de las sociedades postindustriales. En el terreno demográfico, aunque las ciudades siguen creciendo y los pueblos continúan perdiendo población, se está produciendo un goteo constante de urbanos que han fijado definitiva o temporalmente su residencia en los pueblos. Esta población neorrural está formada principalmente por jubilados, jóvenes alternativos y adultos de alta o media extracción social. A estos cambios estructurales está acompañando otro muy importante relativo a los valores (Inglehart, 1991). Los viejos valores modernos que enfatizaban la seguridad y el bienestar económico están siendo sustituidos por otros postmodernos que apuestan, entre otras cosas, por la calidad de vida.

\footnotetext{
3: En este sentido, dice De Marliave (2003, p. 174) que "en el inconsciente colectivo pirenaico hay una incomprensión basada en viejos resentimientos contra las gentes de las ciudades". Lefebvre (2000, p. 145), por su parte, asegura que las revueltas de los montañeses no se han dado exclusivamente con la modernización pues no habría que olvidar, por ejemplo, el éxito de la herejía cátara. Todas ellas tienen algo en común: "las constantes rebeliones y revueltas son el resultado de la protesta y contestación de lo que se les hace llegar desde el Estado, las ciudades o los poderes impuestos"

4: Dice Berot (2006, p. 73) al respecto que "el plan de la ministra de Medio Ambiente francés es tener pastores funcionarios que guarden los ganados de la República, los cuales se encargarán de mantener limpia la montaña con sus caminantes y de servir de comida al lobo y al oso"
} 
Si en el plano económico las ciudades son ya menos agresivas con los pueblos y la naturaleza, en el plano de los valores pasa algo parecido.

Los valores postmaterialistas animan el denominado turismo rural que promocionan las administraciones y los mercados convirtiendo a los pueblos en objetos de consumo de las ciudades y creando relaciones jerárquicas (sujeto/objeto) con ellas. Sin embargo, forma parte también de la influencia postmaterialista la visita de los antiguos residentes, de sus hijos o de otros que conocieron el pueblo, establecieron relaciones y lo visitan a menudo. Si el turismo de masas se centra en paisajes y arquitecturas interesantes este otro tiene como epicentro la fiesta del verano. Aquél es evaluado estratégicamente desde un punto de vista económico (pues el desarrollo de los pueblos se planea en gran medida desde este lado) mientras que este otro es simplemente experimentado en su gratificante dimensión social (ya que visitantes y residentes generan densas y creativas relaciones sociales). Aquél tiende a dejar que lo propio se valore en términos de objeto y a ver al otro también como un objeto (tal como hacen los comercios incrementando el precio a los turistas) mientras que este otro turismo fomenta una relación más igualitaria entre sujetos. Finalmente, si el turismo de masas trata con una realidad simulada (construida con todos los aderezos necesarios para el disfrute del urbanitas), el residente de verano experimenta una realidad que contribuye conscientemente a producir.

Quizás parezca que la relación urbano/rural de la que es expresión el turismo de masas y que la misma Administración contribuye a afianzar es demasiado enemigo para la reacción urbano-rural que trae consigo el veraneante (Bergua, 2009). Sin embargo, no es poca cosa esta mezcla informal entre lo urbano y lo rural. Lo prueba el hecho de que esa mezcla puede observarse en más ámbitos. Por ejemplo, en el complejo mundo de los movimientos de población. En una primera frase, coincidente con la modernización, que aún dura, los pueblos padecieron la emigración. Esta experiencia está grabada en la memoria colectiva de la gente de los pueblos y aún hoy funciona a modo de hábito mental a la hora de opinar acerca de su estilo de vida de vida y el urbano. No sólo porque hay más riqueza y posibilidades de promoción social allí, sino porque el estilo y calidad de vida es mejor. Esa época podemos considerarla hoy parcialmente superada. Entre los adultos y los jóvenes hay cierta tendencia a permanecer en el pueblo a la que acompaña una apropiación de algunas pautas de conducta y hábitos traídos por la modernización urbana. Por otro lado, hay un goteo lento pero constante de gente que viene de las ciudades atraída por un estilo de vida que consideran mejor que el urbano. Los nativos lo perciben, lo aceptan y eso sirve para mejorar su autoestima. Además, los propios habitantes de los pueblos suelen combinar los estilos de vida urbano y rural Si tradicionalmente sucedía que se trabajaba donde se vivía, en la actualidad nos encontramos con bastantes casos en los que se disocia la residencia y el trabajo. Por un lado, están aquellos que tienen su lugar de residencia en el pueblo y trabajan fuera. También están quienes deciden vivir fuera e ir a trabajar al pueblo.

En definitiva. En las relaciones entre la ciudad y los pueblos, los nuevos valores postmaterialistas y el entorno postindustrial se abren dos posibilidades. Por un lado, hay una realidad instituida, amparada por la Administración y el mercado, en las que se perfecciona la vieja lógica de la modernización y, en consecuencia, los pueblos siguen degradándose a la par que se convierten en meros simulacros. A esta realidad podemos denominarla rururbana y se caracteriza por el hecho de que la supervivencia e incluso el crecimiento económico, por ejemplo, los que aporta el turismo de masas, traen inevitablemente consigo cierta degradación social y cultural de los pueblos, así como de 
las relaciones con las ciudades, entre otras razones porque el turista ve el pueblo como un espectáculo o lugar de descanso y el autóctono ve a aquél como una fuente de la que extraer beneficios. La otra realidad descubierta tiene un carácter instituyente pues no está impulsada o tutelada por la Administración o el mercado sino por las gentes. Se caracteriza por facilitar una unión o mezcla no jerárquica entre los pueblos y las ciudades. Este otro modo de relación quizás no sea tan rentable económicamente para los pueblos como el anterior, pero sí que supone un gran capital sociocultural para su supervivencia a largo plazo. A esta realidad podemos denominarla neorrural.

El mundo rururbano está construido a partir de una distinción jerárquica (ciudad/pueblo) que alumbra un amplio abanico de sociabilidades, todas ellas con gran cobertura y apoyo institucional. El mundo neorrural, en cambio, genera mezclas e hibridaciones (ciudades-pueblos) que también están en la base de una amplia gama de sociabilidades, aunque no cuenten con mucho apoyo y respaldo de la trama institucional. Un ejemplo de ese otro modo de relación son los híbridos urbano-rurales que han combinado ambos componentes, tanto si han decidido residir principalmente en las ciudades o en los pueblos. En cualquiera de los casos la hibridación genera estilos de reflexión, actividades artísticas, formas de acción política, etc. singulares. Sin embargo, las relaciones de acoplamiento y cohabitación son imposibles para el orden que tenemos. Para él los pueblos son, como hemos dicho, simplemente objetos (de explotación, inspiración ideológica, disfrute estético, etc.) y la hibridación sólo es posible entre sujetos.

Mi propia existencia encarna ese conflicto. Soy un híbrido urbano-rural porque nací en un pueblo de los Pirineos, fui a estudiar a una gran ciudad, resido en otra, pero vuelvo a menudo y mantengo fuertes vínculos con el entorno en el que crecí. La hibridación de la que soy portador es precisamente la responsable del análisis e interpretación del conflicto del oso en el que se basa este artículo. Más allá de su calidad, el hecho de que dichos análisis e interpretaciones no hayan tenido ningún eco entre los expertos encargados de gestionar la introducción del oso ni entre los políticos que la avalan, muestran la imposibilidad de que lo híbrido sea tenido en cuenta por un orden que se ha instituido a base de distinciones y jerarquías, en este caso entre la ciudad y los pueblos. Sin embargo, a pesar de ese orden, un texto emparentado con estas líneas resultó premiado, lo que mostraría que lo urbano/rural sí es capaz de tratar cálidamente con lo urbano-rural y reconocerlo. Nada más lejos de la realidad. El texto premiado tenía el formato de un ensayo, lo que facilita una lectura más abierta, exótica e incluso arriesgada. El premio fue entonces un ejemplo de la flexibilidad y benevolencia que puede permitirse el consistente y bien implantado orden rural/urbano instituido. Esto incluso le sirve para confirmar su superioridad 5 .

\section{Lo neorrural imposible}

Desde el punto de vista ensayado en este último épigrafe, el oso es real porque también hace entrar en juego (a través de mi propia existencia y lo que desde ella he escrito sobre

\footnotetext{
5: Una explicación idéntica propone Bourdieu (2008) de un acto institucional celebrado en su tierra del Béarn (Pirineo francés) en el que el personaje principal, desafiando la distinción que no sólo pone a la lengua francesa por encima y al occitano por debajo, sino que considera a ésta un habla degradada que conviene evitar (por eso se llama patois, término que significa "hablar con las patas" y que los autóctonos también utilizan para referirse a su propia lengua), se puso a hablar frente al público en occitano.
} 
el conflicto del oso) una relación amistosa y no jerárquica entre lo pueblos y las ciudades que la modernidad no ha querido, sabido ni podido tener del todo en cuenta, pues siempre apostó por lo rururbano que resulta de la dominación de los pueblos por las ciudades. Conviene añadir que, en general, al margen del conflicto del oso, lo neorrural y lo rururbano son dos modos de relación entre pueblos y ciudades de los que resultan sujetos, sociabilidades, valores, etc. que pueden darse en ambos hábitasts e incluso estar presentes conjuntamente en cada uno de ellos, unas veces llevándose bien (rurbano-neorrural) y otras mal (rurbano/neorrural), siendo el primer tipo de relación un nuevo foco de imposibilidad, que sin duda también incorpora el oso en tanto que real, pero que excede el propósito de este ya demasiado alambicado artículo.

\section{Exoducción}

El caso del oso reintroducido en los Pirineos muestra que lo real no es algo que se opone limpia y simétricamente a lo conocido y manejable. Más bien acosa al mundo instituido por muchos flancos y de modos muy diversos. El problema es que, dicho mundo, en lugar de reconocer su ignorancia e inoperancia, proyecta imágenes primero y discursos después para tapar los boquetes. Un modo de recuperar el real es desencantar el mundo, deconstruirlo, mostrar el trabajo de construcción, destapar la red de intereses en los que se apoya y a los que sirve, exhibir sus arbitrarios fundacionales. Los análisis que hemos propuesto apuntan en esa dirección. Otra opción, sería mostrar cómo lo real retorna "bajo la forma de apariciones espectrales" (Zizek, 2003, p. 31).

Cuando Marx y Engels escribían en el Manifiesto Comunista "un espectro recorre Europa...", estaban haciendo referencia a lo "real" que se resistía a la simbolización e ideologización que ejecutaba el nuevo orden social (Derrida, 2003). De este modo, no sólo mostraban el carácter incompleto de dicho orden. También estaban convocando a un espectro que figuraba lo real y, a la vez, le ofrecían un cuerpo para que se encarnara. Como es bien sabido, en el Manifiesto al espectro se le llama "comunismo" y se sugiere que debe encarnarse en el "proletariado".

En relación con el conflicto del oso, muchos son los espectros que pueden aparecer porque, como hemos visto, muchas son también las dimensiones de lo real que se le resisten al plan institucional. Pero, puestos a elegir, si con relación al capitalismo hay un espectro comunista, en la construcción urbana del oso y de los Pirineos el espectro bien podría ser la “montañeidad”. En cuanto al agente en el que podría encarnarse, quizás aquél en el que se mezcle e hibride de distintos modos lo urbano y lo rural. 


\section{Referencias}

Benhammou, F. (2005). Vendre la peu de l'ours avant de l'avant sauvé?. En: Benhammou, F., Bobbé, S., Camarra, J-J. y Reunes, A., L'ours des Pyrenées. Les 4 vérités. Toulouse: Éditions Privat, 77-120.

Benhammou, F., Mermet, L. (2003). Strategie et geopolitique de l'opposition a la conservation de la nature: le cas de l'ours des Pyrinees. París: Natures, Sciences, Societes, 11(4), 381-393.

Bergua, J. A. (2009). Naturalismo, culturalismo y poder: Notas para una sociología del paisaje. Madrid: Revista Española de Sociología, 11, 79-100.

Bergua, J. A. (2015). Postpolítica. Elogio del gentío. Madrid: Biblioteca Nueva.

Bérot, V. (2006). L’ours: les raisons de la colére. Pau: Editions Cairn.

Biarge, F. y Biarge A. (2000). Pirineístas franceses (1871-1895). Zaragoza: Prames.

Bobbé, S. (2005). L'ours des Pyrenées, un sauvage parmi d'autres. En: Benhammou, F., Bobbé, S., Camarra, J-J. y Reunes, A., L'ours des Pyrenées. Les 4 vérités. Toulouse: Éditions Privat, 123-146.

Bourdieu, P. (2008). ¿Qué significa hablar?. Madrid: Akal.

Callon, M. (1986). Some elements of a sociology of translation: domestication of the scallops and the fishermen of St Brieuc Bay. En: Law, J., Power, action and belief: a new sociology of knowledge? Londres: Routledge, 196-223.

Camarra, J-J. (2005). Biologie, ecologie, comportement de l'ours brun. En Benhammou, F., Bobbé, S., Camarra, J-J. y Reunes, A., L'ours des Pyrenées. Les 4 vérités. Toulouse: Éditions Privat, 15-36.

Casanova, E. (1997). L'os del Pirineu, crónica d'un extermini. Llérida: Pagès editors.

Deleuze, G. y Guattari, F. (1985). El Anti-Edipo. Capitalismo y Esquizofrenia. Buenos Aires: Paidós.

De Marliave, O. (2003). Histoire de l'ours dans les Pyrenées.De la préhistoire à la rréintroduction. Bordeaux: Editions Sud Ouest.

Derrida, J. (2003). Espectros de Marx. Madrid: Trotta.

Derrida, J. (2008). El animal que luego estoy si(gui)end. Madrid: Trotta.

Descola, Ph. (2006). Par delà nature et culture. París: Gallimard. 
Doniger, W. (2005). Zoomorphism in Ancient India. Humans More Bestial than Beasts En: Daston, L. y Mitman, Thinking with Aanimals. New York: Columbia University Press, 18-36.

Freud, S. (1993). Textos de psicoanálisis. Madrid: Altaya.

Getty, A. (1996). La diosa. Madre de la naturaleza viviente. Madrid: Debate.

Heidegger, M. (1993). Ser y Tiempo. Buenos Aires: Planeta-Agostini.

Ibáñez, J. (1991). Comunicaciones entre los pueblos y la ciudad. Madrid: Política y Sociedad, 8, 95-100.

Inglehart, R. (1991). El cambio cultural en las sociedades industriales avanzadas. Madrid: CIS.

Keswick, M. (1993). El arte del jardín. Madrid: El Paseante, 20(22), 48-60.

Lacan, J., (1992a). El seminario, 17. El reverso del psicoanálisis. Buenos Aires: Paidós.

Lacan, J. (1992b). El seminario, 20, Aún. Buenos Aires: Paidós.

Lagalisse, Y. Quenette, P-Y, Rech, J. y Lignereux, Y. (2003). Etude croposcopique du regime alimentaire d'une population d'ours bruns reintroduite dans les Pyrinees (1996-99). París: Revue de Médecine Veterinaire, 150(10), 639-644.

Lefebvre, H. (2000). Pyrenées. Pau: Editions Cairn.

Latour, B. (2005). Reensamblar lo social. Una introducción a la teoría del actor-red. Buenos Aires: Manantial.

Moyano, E. (2000). Procesos de cambio en la sociedad rural española. Pluralidad de intereses en una nueva estructura de oportunidades. Barcelona: Papers, 61, 191220.

Nante, B. (2011). El libro rojo de Jung. Claves para la comprensión de una obra inexplicable. Madrid: Siruela.

Rifkin, J. (2002). La economía del hidrógeno. Buenos Aires: Paidós.

Sainz De La Maza, P.; Nunes Alonso, J. (2001). Los sistemas de información geográfica aplicados al estudio, la gestión y la conservación del hábitat del oso pardo en un área del pirineo catalán. Barcelona: Treballs de la Societat Catalana de Geografia, 52, 245-264.

Simondon, G. (2008). Dos lecciones sobre el animal y el hombre. Buenos Aires: La Cebra.

Stavrakakis, Y. (2010). La izquierda lacaniana, Psicoanálisis, teoría, política. Ciudad de México: Fondo de Cultura Económica.

Trías, E. (1999). Lo bello y lo siniestro. Madrid: Ariel. 
Watzlawick, P. (1995). El sinsentido del sentido o el sentido del sinsentido. Barcelona: Herder.

Wilber, K. (1989). El proyecto Atman. Barcelona: Kairós.

Williams, R. (2002). El campo y la ciudad. Buenos Aires: Paidós.

Zizek, S. (2003) El espectro de la ideología. En: Zizek, S. (comp.), Ideología. Un mapa de la cuestión. Ciudad de México: Fondo de Cultura Económica, 7-42. 